University of Nebraska - Lincoln

DigitalCommons@University of Nebraska - Lincoln

Faculty Publications, Department of Psychology

Psychology, Department of

April 1993

\title{
Relations Between Social Skills and High-Risk Sexual Interactions Among Adolescents
}

Douglas W. Nangle

University of Mississippi Medical Center

David J. Hansen

Univertsity of Nebraska-Lincoln, dhansen1@unl.edu

Follow this and additional works at: https://digitalcommons.unl.edu/psychfacpub

Part of the Psychiatry and Psychology Commons

Nangle, Douglas W. and Hansen, David J., "Relations Between Social Skills and High-Risk Sexual Interactions Among Adolescents" (1993). Faculty Publications, Department of Psychology. 195. https://digitalcommons.unl.edu/psychfacpub/195

This Article is brought to you for free and open access by the Psychology, Department of at DigitalCommons@University of Nebraska - Lincoln. It has been accepted for inclusion in Faculty Publications, Department of Psychology by an authorized administrator of DigitalCommons@University of Nebraska - Lincoln. 
Researchers have begun to employ social-skills training in efforts to change the sexual behavior of adolescents. However, despite the promise of social-skills training, little is known about how social skills are related to the sexual practices of adolescents. The present article reviews the current literature and proposes a conceptual framework for understanding the relations between social skills and sexual behavior of adolescents by (a)examining the relationship between sexual activity and social skills, (b) examining the development of sexual-interaction skills and deficits, (c) summarizing what is currently known about the relations between social skills and sexual behavior, (d) discussing current issues in the assessment and treatment of sexual-interaction skills deficits, and (e) proposing some directions for needed research that will add both to our current knowledge base and to the effectiveness of applied intervention efforts.

\title{
Relations Between Social Skills and High-Risk Sexual Interactions Among Adolescents
}

Current Issues and Future Directions

\author{
Douglas W. Nangle \\ University of Mississippi Medical Center \\ David J. Hansen \\ University of Nebraska-Lincoln
}

Acquired immune deficiency syndrome (AIDS) has revitalized society's interest in the sexual behavior of adolescents. Although AIDS has captured most of society's attention, sexually active adolescents face a range of serious health risks. The current epidemic of sexually transmitted diseases (STDs) is the major health threat faced by adolescents today (MacDonald et al., 1990; Select Committee on

Authors'Note: We would like to thank Dr. Joseph R. Scotti for his input and feedback on an earlier version of this article. Special thanks to Rebecca E. Carr for her thoughtful and frequent feedback on a number of versions of this article. Thanks also to Catherine A. Martin and Jody E. Warner for their comments on an earlier draft. 
Children, Youth, and Families [Select Committee], 1988). An estimated 2.5 million teenagers are affected by STDs each year (DiClemente, 1990; Jemmott \& Jemmott, 1990). This alarming figure has raised new concerns about the number of teenagers possibly infected with the AIDS virus (MacDonald et al., 1990; Select Committee, 1988). Rates of teen pregnancy have reached epidemic proportions, with almost one half of all teenage women becoming pregnant before the age of 20 (Beck \& Davies, 1987; Koenig \& Zelnick, 1982; Select Committee, 1988). In addition, society is becoming increasingly aware of the prevalence of such problems as date rape among adolescents (e.g., Lundberg-Love \& Geffner, 1989; Muehlenhard \& Linton, 1987; Murnen, Perot, \& Byrne, 1989).

The current AIDS health crisis has brought an increasing urgency to the search for interventions capable of changing the sexual practices of adolescents (e.g., Goodman \& Cohall, 1989; Huszti, Clopton, \& Mason, 1989; Kelly \& St. Lawrence, 1988; Melchert \& Burnett, 1990). One promising approach appears to be the combination of behavioral-skills training and knowledge-based education efforts (Hingson, Strunin, Berlin, \& Heeren, 1990; Huszti et al., 1989; Kelly \& St. Lawrence, 1988; Lundberg-Love \& Geffner, 1989; MacDonald et al., 1990; Melchert \& Burnett, 1990; Muehlenhard \& Linton, 1987; Roscoe \& Kruger, 1990). For example, interventions combining knowledge-based education with social-skills training have effectively produced changes in the contraceptive behavior of adolescents (e.g., Schinke, Blythe, \& Gilchrest, 1981) and the highrisk sexual behavior of homosexual men (e.g., Kelly, St. Lawrence, Hood, \& Brasfield, 1989).

The effectiveness of interventions that include social-skills training is not surprising, because the modification of high-risk sexual behavior requires concomitant changes in social behavior (Huszti et al., 1989; Kelly \& St. Lawrence, 1988; MacDonald et al., 1990). Attempts to reduce high-risk sexual behavior should include discussing safer-sex practices with a partner, resisting coercive attempts to engage in high-risk behaviors, and problem solving to avoid risky social situations (Kelly \& St. Lawrence, 1988).

Despite the promise of social-skills training, little is known about how social skills are related to the sexual practices of adolescents. 
The present article will provide a conceptual framework for understanding the relations between social skills and many of the problems associated with the sexual activity of adolescents, such as STD transmission and date rape. The central hypothesis of this conceptualization is that problems such as STD transmission and date rape are at least in part due to problematic heterosocial interactions between adolescents (e.g., miscommunication between partners). The heterosocial skills required for competent sexual interactions will be referred to as sexual-interaction skills (e.g., assertively requesting that a partner use a condom). Employing a social-skills conceptualization, problematic heterosocial-sexual interactions would thus result from deficits in sexual-interaction skills. Although these hypotheses are intuitively pleasing, few studies have tested them directly (e.g., Bruch \& Hynes, 1987; Hynes \& Bruch, 1985; Schinke et al., 1981). Research examining the relations between sexual-interaction skills and the many problems associated with the sexual activity of adolescents is extremely important for understanding and intervening to change the sexual practices of adolescents.

This article proposes a conceptual framework for understanding the relations between social skills and sexual behavior of adolescents by (a) examining the relationship between sexual activity and social skills, (b) examining the development of sexual-interaction skills and deficits, (c) summarizing what is currently known about the relations between social skills and sexual behavior, (d) discussing current issues in the assessment and treatment of sexual-interaction skills deficits, and (e) proposing some directions for needed research that will add both to our current knowledge base and to the effectiveness of applied intervention efforts.

Before proceeding further, it is necessary to acknowledge some of the limitations of this article. The problems associated with adolescent sexual activity are extraordinarily complex, and this conceptualization and review focuses primarily on the social aspects. Only heterosexual activity is discussed, because of both limitations in space and the paucity of available information regarding adolescent homosexual activity. Finally, the review is selective because of the wide variety of literatures examined; however, when possible, the reader is referred to additional sources. 


\section{THE RELATIONSHIP BETWEEN SEXUAL BEHAVIOR AND SOCIAL SKILLS}

Adolescence is a period marked by the onset of puberty and the emergence of sexual activity. For example, as many as $50 \%$ of $15-$ to 19 -year-olds may be sexually active, and, by the age of 19 , this figure may increase to over 70\% (Select Committee, 1988). The physical changes of puberty clearly play an integral role in this emergent sexual activity (Berger, 1986; Chilman, 1983). However, the biological changes of puberty explain little about the complexities of adolescent sexual behavior. Indeed, adolescent sexual behavior might be influenced more heavily by social expectations and the social significance of patterns of sexual activity than by actual biological factors (e.g., Ford \& Beach, 1951; Gagnon \& Simon, 1973; Miller, McCoy, \& Olson, 1986). Sexual behavior is indeed social, as are many of the behaviors that precede, maintain, and follow it (Barlow, 1977; Gagnon \& Simon, 1973).

The sexual behavior of adolescents cannot be understood adequately apart from its social context. This social context is continually changing throughout adolescence. Changes in the social interactions and relationships with same- and opposite-sex peers create new and demanding challenges for the developing adolescent. The continued development of competent social skills is critical for both the social and the sexual adjustment of adolescents. Social skills can be defined, generally, as the learned interpersonal behaviors that individuals use to obtain or maintain reinforcement from other people (Kelly, 1982). These skills become increasingly important for the adolescent, as the influence of the peer group increases markedly (Berger, 1986; Gagnon \& Simon, 1973). The adolescent's peer group becomes larger and more complex, and more time is spent with peers (Berger, 1986; Gagnon \& Simon, 1973; Kelly \& Hansen, 1987).

The increased frequency and importance of opposite-sex interactions and emergent sexuality place additional demands on the developing adolescent (Gagnon \& Simon, 1973; Kelly \& Hansen, 1987). These demands require the development of a new and more specialized subset of social skills, referred to as heterosocial skills. Heterosocial skills can be defined as the skills necessary for initi- 
ating, maintaining, and terminating social and sexual relationships with persons of the opposite sex (Barlow, Abel, Blanchard, Bristow, \& Young, 1977; Galassi \& Galassi, 1979). These skills serve a variety of important functions for the adolescent, including (a) the promotion of interpersonal competence and adult-like social behavior; (b) recreation, including entertainment and sexual stimulation; (c) the enhancement of status within the peer group; (d) the development of independence assertion; (e) experimentation with sex-role behaviors and sexual activity; and (f) courtship and mate selection (Damon, 1983; Kelly \& Hansen, 1987).

Despite the importance of heterosocial skills in the development of adolescent sexuality, the current heterosocial-skills literature is generally limited to the narrow range of skills involved in date initiation (Barlow, 1977; Hansen, Christopher, \& Nangle, 1992). The skills required in different stages of relationships, interactions surrounding sexual activity, and heterosocial friendships have been largely ignored (Hansen et al., 1992). Barlow (1977) noted the failure of the heterosocial-skills literature to address the social behaviors involved in sexual interactions, and this facet of social skill remains virtually uninvestigated at present. No doubt, the many ethical and methodological issues involved in the study of sexual interactions, especially with adolescents, are major obstacles to this type of research. Additional limitations of the current heterosocial-skills literature are addressed in more detail in subsequent sections of this article.

\section{Development of Sexual-Interaction Skills}

Attempts to understand any aspect of adolescent development are made difficult by the many changes occurring both within and outside the individual (Peterson \& Hamburg, 1986). The development of sexual-interaction skills occurs in a complex and continually changing context. The major developmental changes influencing the socialsexual behavior of adolescents include the physical changes of puberty, increasing cognitive capabilities, and changing social interaction patterns and expectations (Berger, 1986; Chilman, 1983; Gagnon \& Simon, 1973). A thorough review of the developmental factors influencing adolescent social-sexual behavior is clearly beyond the scope 
of the present article. A more complete account of these factors can be found in Chilman (1983) or Gagnon and Simon (1973). The present conceptualization will, however, address the more salient developmental factors influencing sexual-interaction skills.

Sexual-interaction skills are hypothesized to develop through the same mechanisms thought to be involved in the development of other social behaviors (Barlow, 1977; Hansen et al., 1992; Hartup, 1983; Kelly \& Hansen, 1987). Behavioral models of social-skills development are based on the major assumptions of social-learning theory (Bandura, 1969). Social skills are viewed as learned behaviors that result from the interactions between individuals and their environment. From this perspective, sexual-interaction skills are acquired through a complex interaction of learning mechanisms. These mechanisms include (a) exposure to appropriate sexual-interaction skill models; (b) the consequences (e.g., reinforcement, punishment, extinction) associated with an adolescent's sexual-interaction behavior; (c) exposure to, and participation in, peer social and sexual activities; and (d) "cognitive" factors such as self-statements and attributional processes (Hansen et al., 1992; Kelly, 1982).

Adolescence is characterized by dramatic changes in heterosocial interactions. For example, Csikszentmihalyi and Larson (1 984) found that high school freshmen spent $44 \%$ of their time in same-sex groups and $4 \%$ in opposite-sex dyads, whereas seniors spent $21 \%$ of their time in same-sex groups and $24 \%$ in opposite-sex dyads. Thus, for the younger adolescent, the majority of opportunities for learning sexual-interaction skills stem from indirect learning experiences, with the family, same-sex peers, and media as the mediating agents (Chilman, 1983; Gagnon \& Simon, 1973). Adolescents typically begin dating between the ages of 13 and 15 years, and, as might be expected, the degree of sexual involvement is strongly related to the degree of dating involvement (e.g., Miller et al., 1986). The onset and increasing frequency of dating during this period provide more frequent opportunities to learn sexual-interaction skills through direct exposure to heterosocial-sexual interactions. In addition, the double dating and group dating common in early and middle adolescence permit teenagers to learn some sexual-interaction skills by modeling from peers (Kelly \& Hansen, 1987). The older adolescent is increasingly influenced by same-sex and opposite-sex peers, as the influence of the family and media is reduced (Gagnon \& Simon, 1973). 


\section{Sexual-Interaction Skills Deficits}

Using a social-skills conceptualization, problematic heterosocial-sexual interactions result from the failure of adolescents to exhibit competent sexual-interaction skills in high-risk situations. The failure to exhibit a sexual-interaction skill can be explained in two different ways: (a) The skill was never learned or was inadequately learned, or (b) the skill was learned (i.e., in the repertoire of responses), but is used effectively only in certain situations because of prior reinforcement, punishment, or extinction of the behavior or because of inadequate discrimination regarding when to exhibit the skill (Kelly, 1982).

Considering the learning mechanisms involved in the acquisition of sexual-interaction skills, it seems likely that many adolescents would fail to learn or would inadequately learn these skills (Kelly \& Hansen, 1987). The onset of sexual activity typically coincides with the increased independence of the adolescent (Gagnon \& Simon, 1973). The influence of parents decreases, as the influence of the peer group increases. The prevalence of problems associated with adolescent sexual activity suggests that peers may not be the most appropriate education agents (Chilman, 1983; Hartup, 1983; Kelly \& Hansen, 1987). Lack of information about basic physiology, STDs, and contraception are believed to be common problems among adolescents (e.g., Oskamp \& Mindick, 1983; Select Committee, 1988). In addition, most sexual behavior occurs in privacy, which further limits the influence of modeling on learning sexual-interaction skills.

Learning sexual-interaction skills by direct exposure to sexual interactions poses many problems for the developing adolescent. The acquisition of social behavior is partly dependent on operant learning processes (Hansen et al., 1992; Kelly, 1982). A skill is acquired and then used in an interaction. Feedback is provided by peers or adults, and this feedback serves to reinforce, modify, or punish the use of the skill. This "trial and error" process may not be available to the adolescent in the acquisition of sexual-interaction skills. The adolescent's failure to be assertive about using a condom during intercourse on one occasion could result in such serious consequences as HIV infection or unwanted pregnancy. For example, Koenig and Zelnick (1982) found that, within the first two years of intercourse, as many as $35.9 \%$ of sexually active teenage girls become pregnant. 
The complex contingencies involved in the acquisition of sexual-interaction skills are likely to pose many difficult developmental challenges for the adolescent. Adolescents are more likely to be influenced by immediate positive consequences than by delayed negative consequences because of their tendency to think in terms of the present and their limited comprehension of the effects of present behavior on future outcomes (Berger, 1986). The positive consequences of sexual activity are often immediate (e.g., physiological responses, peer group responses), whereas the negative consequences are somewhat delayed (e.g., pregnancy, STDs) (Chilman, 1983). Sexual intercourse is not only reinforcing physiologically, it is also a status-gaining behavior for both males and females (McCabe, 1984). It is probable that even incompetent sexual-interaction behaviors often produce reinforcing outcomes for the adolescent. For example, an adolescent's aggressive advances might be reinforced inappropriately by coerced sexual activity. Similarly, an adolescent might fail to inform a partner about the possibility of STD transmission and the need for condom use, yet still engage in sexual intercourse. The failure of this adolescent to use a sexual-interaction skill is reinforced by the immediate positive consequences associated with sexual activity and the response of the peer group. In this example, the more delayed consequences of not using a condom, such as STD transmission or pregnancy, would be less likely to influence the adolescent's behavior.

Even if an adolescent has acquired competent sexual-interaction skills, he or she might fail to exhibit them in certain situations because of exposure to differential reinforcement or punishment of the skills or because of inadequate discrimination regarding when to exhibit the skills (Kelly, 1982). For example, the adolescent might receive praise for honesty from one sexual partner for disclosing that he or she has an STD, whereas another partner might punish the disclosure by withdrawing from sexual activity. The failure to use a sexual-interaction skill might also be caused by an inability to identify or discriminate those situations in which it is needed. The adolescent might fail to insist that the partner use a condom because he or she has "known" that partner for years. Another ex- 
ample might be a male who fails to discriminate his partner's verbal requests to "stop" as meaning "do not have sex with me" rather than "do it, I am just playing hard to get" (e.g., Check \& Malamuth, 1983; Muehlenhard \& Linton, 1987).

Adolescents might experience additional difficulty in discriminating when to use sexual-interaction skills because of cognitive limitations (Berger, 1986). For example, adolescents may not be able to comprehend the probabilities of conception that result from unprotected intercourse (Oskamp \& Mindick, 1983) or might believe that they are immune to the consequences of their sexual behavior and that only other people can get pregnant or contract the AIDS virus (Hansen et al., 1992). Such cognitive limitations might place the adolescent at increased risk, as recent evidence suggests perceived susceptibility to AIDS is negatively related to high-risk sexual behavior (Catania, Kegeles, \& Coates, 1990; Goodman \& Cohall, 1989).

Another possibility is that the adolescent has acquired competent sexual-interaction skills, but anxiety inhibits their use in specific sexual situations. Over $30 \%$ of college men and women report that heterosocial anxiety is a significant dating problem (Arkowitz, Hinton, Perl, $\&$ Himadi, 1978). Given the high prevalence of heterosocial anxiety in the adolescent population, it seems likely that anxiety plays a role in the development of sexual-interaction problems. Leary and Dobbins (1983) suggest that sexual interactions are characterized by a number of factors that are likely to exacerbate heterosocial anxiety. Sexual interactions tend to be ambiguous, engender fears of negative evaluation based on performance or appearance, and induce high levels of selfdisclosure and self-awareness. Adolescents with high levels of heterosocial anxiety have been found to be less sexually experienced, engage in sexual activity less frequently, have fewer sexual partners, be less likely to engage in oral sex, be more apprehensive about sex, and have a higher incidence of sexual dysfunction (e.g., premature ejaculation) than adolescents with low levels of heterosocial anxiety (Leary \& Dobbins, 1983). Further, degree of heterosocial anxiety has been found to be negatively correlated with frequency of discussion regarding contraception, partner's communication effectiveness, and the use of more effective contraceptive methods (Bruch \& Hynes, 1987). 


\section{CURRENT ISSUES IN THE ASSESSMENT OF SEXUAL-INTERACTION SKILLS}

\section{Limitations of the Current Heterosocial-Skills Literature}

Given the close relation between social skills and sexual interactions, the existing heterosocial-skills literature would appear to be a fruitful starting point in the search for assessment procedures and intervention targets. However, current conceptualizations of heterosocial competence are based on the problems associated with minimal dating, and assessment has focused mainly on the conversation skills needed in date initiation (Hansen et al., 1992). The failure of heterosocial-skills researchers to address the social aspects of sexual interactions has resulted in the creation of an artificial dichotomy in the heterosocial-skills literature, composed of "social" and "sexual" interactions (Conger \& Conger, 1982). The failure to address sexual interactions is particularly disturbing, considering reports by adolescents that the social interactions surrounding sexual activity are the most problematic of heterosocial situations (Conger \& Conger, 1982; Knox \& Wilson, 1983; Muehlenhard \& Linton, 1987).

There appear to be some valid reasons for this emphasis on the conversation skills involved in date initiation. The initial surge of interest in minimal dating in the 1970s was not motivated by a pure interest in heterosocial dysfunction. Heterosocial anxiety was selected as an ideal analog for anxiety research, because of its clinical relevance, large number of available subjects (college students), negligible demand effects, and the strong and not readily habituated physiological response elicited by heterosocial situations (Curran, 1977). In addition, separating conversation skills from sexual interactions eliminates some potential methodological problems associated with the assessment of sexual behavior. Sex researchers have been forced to rely heavily on self-report methods because of ethical and methodological concerns. This reliance on self-report raises two important questions: (a) What is the relationship of self-report to other behavioral and physiological response systems? and (b) How do assessments using contrived situations to assess the three response systems (i.e., behavioral, cognitive, physiological) compare to actual sexual interaction behavior? (Barlow, 1977). 


\section{Assessment of Sexual-Interaction Skills}

Clearly, sexual-interaction skills researchers will need to develop methods capable of assessing specific skills that address these difficult ethical and methodological issues. This will include the further development and validation of promising assessment methods from the existing heterosocial-skills literature. Some of the more promising measures for sexual-interaction skills assessment include self-monitoring, self-ratings of anxiety or skill, and peer assessment (i.e., ratings by significant others) in the natural environment (cf. Arkowitz, 1977; Galassi \& Galassi, 1979; Hansen et a]., 1992). These methods do address some of the ethical and methodological problems involved in the assessment of sexual behavior; however, existing evidence suggests that both self-monitoring and self-ratings of social skill and anxiety suffer from high reactivity and low reliability, whereas the psychometric properties of peer assessments are not known at this time (Hansen et al., 1992).

The need for sexual-interaction skills assessment research is evidenced by the few studies that set out to assess such skills and the resulting lack of refined assessment procedures. Much of the existing evidence for relations between social skills and problems related to adolescent sexual activity has been extrapolated from studies that did not actually assess specific sexual-interaction skills (e.g., Balassone, 1989; Burger \& Inderbitzen, 1985; Cvetkovich \& Grote 1981; Muehlenhard \& Linton, 1987; Murnen et al., 1989; Weisman, Plichta, Nathanson, Ensminger, \& Robinson, 1991). Most of these studies employed self-report measures to examine a number of factors, including social behavior, thought to influence contraceptive behavior (e.g., Balassone, 1989; Burger \& Inderbitzen, 1985; Cvetkovich \& Grote, 1981; Weisman et a]., 1991). However, the use of global selfreport measures (e.g., ratings of "general sexual communication") does not provide information about specific sexual-interaction skills.

In fact, the existing research on contraceptive behavior provides an excellent example of the growing need for the further development and refinement of assessment procedures. Most studies of contraceptive behavior have relied on global self-reports of whether the respondent has ever used contraception or used contraception at first or last intercourse (e.g., Koenig \& Zelnick, 1982; Sonenstein, Pleck, 
$\& \mathrm{Ku}, 1989)$. These global self-reports have a number of major shortcomings, including (a) failure to control for frequency of intercourse or number of sexual partners, (b) inability to discriminate between adolescents who inconsistently use contraception and those who use contraception reliably, (c) inability to discriminate between use of specific types of contraception, and (d) failure to identify specific targets for intervention. For example, adolescents who report having ever used contraception or using contraception at first or last intercourse are likely to compose a heterogeneous group. Adolescents classified in this group could range from individuals who used contraception only once to those who reliably use effective contraception during each sexual encounter. Members of this group might also vary widely in terms of their frequency of sexual intercourse and number of sexual partners. Hence it would not be possible to examine the relations between sexual-interaction skills and varying degrees of contraceptive use. In addition, self-report measures that do not discriminate between specific methods of contraception are not sensitive to potential social skill differences across users of various methods. For example, female adolescents relying on condoms for contraception may be more effective heterosocial communicators than are female adolescents choosing other methods, such as the pill (Cvetkovich \& Grote, 1981). This relationship would be expected, given that a female's reliance on condoms would require more communication between partners than the use of a female-dependent method (i.e., pill).

A promising approach addressing the major weaknesses in current self-report assessment procedures is the development of the Contraceptive Behavior Questionnaire (CBQ; Nangle, Giacoletti, Ellis, Aljazireh, \& Hansen, 1992). The CBQ was developed for use in a descriptive study of the contraceptive behavior of college students (Nangle et al., 1992). A standardized self-report format is used to assess social skills in specific contraceptive situations (e.g., initiating a discussion about contraception with a partner) and the performance of task-analyzed skills required in the use of a variety of specific contraceptive methods (e.g., unrolling the condom fully to the base of the penis). In addition, the CBQ also assesses a number of contextual variables associated with contraceptive use, such as frequency of sexual activity and number of sexual partners. 
The few studies that directly assessed specific sexual-interaction skills employed role-play measures (e.g., Hynes \& Bruch, 1985; Schinke et al., 1981). Role-play procedures allow the direct analog assessment of specific sexual-interaction skills, while remaining sensitive to the ethical concerns, involved in the direct assessment of sexual behavior. For example, Hynes and Bruch (1985) developed a role-play procedure employing simulated problematic contraceptive situations based on Byrne's (1983) model of antecedent tasks proposed to facilitate effective contraceptive behavior: (a) learning about contraception, (b) acknowledging the possibility of sexual activity, (c) obtaining contraception, and (d) discussing birth control with one's partner. Hynes and Bruch (1985) hypothesized that, because of the social nature of these antecedent tasks, an individual's social-skill level (i.e., rights assertion, expression of positive thoughts) would be positively related to the successful negotiation of these antecedent tasks.

In a study designed to test this hypothesis, Hynes and Bruch (1985) had a sample of 87 undergraduates first complete the Reduced Behavioral Role-Play Assertion Test (RBRAT; Schwartz \& Gottman, 1976), which is a measure of rights-assertion skill requiring the subject to generate an immediate verbal response to six situations involving unreasonable requests. Positive self-expression was then assessed using a shortened version of the Behavioral Test of Tenderness Expression (BTTE; Warren \& Gilner, 1978). The BTTE requires the subject to formulate an immediate verbal reply to a simulated dating partner's statement. The performances on the RBRAT and BTTE were then compared to the performances on the Contraceptive Problem Inventory (CPI; Hynes \& Bruch, 1985). The CPI is a behavioral role-play measure of competence in various contraceptive problem situations (e.g., asking a druggist for a particular type of contraceptive foam).

Participants were asked to imagine themselves in a randomly selected contraceptive situation and then to provide a verbal response as if directly interacting with another person. The effectiveness of each response was then rated by judges using a manual developed by the authors. The results provided tentative support for the hypothesized relationship between level of positive self-expression 
and rights-assertion skill and effective verbal responses in the contraceptive role-play situations.

The method used by Hynes and Bruch (1985) is an innovative use of role-play for the assessment of sexual-interaction skills; however, it does have some important limitations. The subjects were both undergraduate and graduate students with a mean age of 20.6 years, so it is hard to determine how the results would apply to younger adolescents. The actual contraceptive behavior of the subjects was not assessed (e.g., through self-report or self-monitoring). The failure to assess actual contraceptive behavior is significant, as the relation between role-play and actual in vivo behavior is questionable (Bellack, Hersen, \& Lamparski, 1979). In addition, given the situation-specific nature of socially skilled behavior (cf. McFall, 1982), the notion that skill in one rights-assertion role-play should be related to the level of that skill in an entirely different situation is indeed questionable. The skills required for an adolescent to refuse a friend's request for a favor might be very different from the skills required for that same adolescent to request that his or her sexual partner use a condom.

Schinke et al. (1981) devised an assessment battery that addresses many of the limitations of the Hynes and Bruch (1985) study. Thirtysix high school sophomores completed an assessment that consisted of (a) tests of awareness of sexual facts, myths, and probabilities; (b) measures of social problem solving; and (c) a behavioral role-play test. The behavioral role-play test engaged individual male and female subjects in interactions with an opposite-sex age-matched confederate. A series of vignettes simulating stressful dating situations (e.g., being asked to spend the night with a date even though neither person uses birth control, having to broach the subject of contraception with a reluctant partner). The interactions were videotaped and later rated by naive observers in terms of specific sexual-interaction skills (e.g., eye contact with opposite-sex partner, declarative "no" responses, refusal statements, requests that partners share responsibility for birth control). The sexual knowledge measures were administered again at 6-month follow-up.

There are several noteworthy aspects of the Schinke et al. (1981) assessment battery, including the use of (a) pre and post self-report 
measures of the actual contraceptive practices of the subjects; (b) younger adolescents as subjects; (c) ratings of videotaped role-play performances that included the assessment of specific sexual-interaction skills (verbal and nonverbal); and (d) assessments of specific sexual-interaction skills in analog situations designed to approximate the situations of interest (i.e., sexual situations). However, the assessment of problem-solving skills was limited to situations unrelated to contraceptive use (i.e., Means-End Thinking Test; Shure \& Spivack, 1972). The assessments reported by both Hynes and Bruch (1985) and Schinke et al. (1981) illustrate some innovative approaches to the assessment of sexual-interaction skills, as well as some of the potential difficulties.

\section{CURRENT ISSUES IN SEXUAL-INTERACTION SKILLS TRAINING}

Despite its limitations, the current sexual-interaction skills assessment literature does provide preliminary evidence suggesting that social-skills deficits and problems associated with adolescent sexual activity (e.g., inadequate contraceptive behavior, teen pregnancy, date rape) are related. These include deficits in (a) communication skills (e.g., Burger \& Inderbitzen, 1985; Cvetkovich \& Grote, 1981 ;Hynes \& Bruch, 1985; Muehlenhard \& Linton, 1987; Murnen et al., 1989; Schinke et al., 1981); (b) assertion skills (e.g., Hynes \& Bruch, 1985; Muehlenhard \& Linton, 1987; Murnen et al., 1989; Schinke et al., 1981; Weisman et al., 1991); and (c) problemsolving skills (e.g., Balassone, 1989; Hynes \& Bruch, 1985; Schinke et al., 1981).

Based on intuition and this preliminary assessment information, many researchers have suggested that social-skills training procedures be included in educational efforts to change the sexual practices of adolescents (e.g., Beck \& Davies, 1987; Huszti et al., 1989; Hynes \& Bruch, 1985; Kelly \& St. Lawrence, 1988; Lundberg-Love \& Geffner, 1989; MacDonald et al., 1990; Muehlenhard \& Linton, 1987). More specifically, this preliminary evidence suggests that the application of communication-, assertion-, and problem-solving skills training would add to the effectiveness of current educational efforts. 
Social-skills training procedures have been used extensively with adolescents for social, nonsexual target behaviors. Recent applications include (a) communication-skills training (e.g., Bradlyn et al., 1983; Hansen, St. Lawrence, \& Christoff, 1989; Plienis et al., 1987); (b) assertion-skills training (e.g., Kirkland, Thelen, \& Miller, 1982; Lee, Hallberg, \& Hassard, 1979; Rhodes, Redd, \& Berggren, 1979; Rotherman \& Armstrong, 1980; Stake, DeVille, \& Pennell, 1983); and (c) problem-solving skills training (e.g., Christoff et al., 1985; Kazdin, Esveldt-Dawson, French, \& Unis, 1987; Tisdelle \& St. Lawrence, 1988). This literature serves as a potential basis for the future development of sexual-interaction skills training procedures.

For example, Schinke et al. (1981) employed a combination of information-based education and social-skills training in an intervention designed to prevent unplanned adolescent pregnancy. Thirty-six high school sophomores (mean age $=15.89$ years) participated in the study. After receiving consent from both the subjects and their parents, students were assigned randomly to one of four conditions of a Solomon group research design: (a) pretest, training, and posttest; (b) training and posttest; (c) pretest and posttest; and (d) posttest only. Subjects in the two training conditions participated in fourteen 50min group training sessions carried out in their school. The assessment procedures used in this intervention are described in the previous section of this review. Guest speakers, audiovisual aids, and discussions were used to provide information on reproductive biology and contraceptive methods. Problem-solving training consisted of teaching subjects to specify problems, generate solutions, evaluate the potential benefits and costs of each generated solution, and plan for the implementation of selected solutions. The training was adapted specifically to sexual decision making (e.g., birth control, pregnancy). The subjects also received communication-skills training that included instruction, modeling, rehearsal, and feedback components. The subjects practiced each communication skill in small groups using role-play and also contracted to practice the skills in pairs outside the training sessions. Compliance with these contracts was monitored at each subsequent session. 
The intervention proved to be very successful. Subjects in the training conditions outperformed control subjects on sexual knowledge tests, problem-solving tests, and the behavioral role-play tests. Ratings of posttraining videotapes of structured role-play performances indicated that the treatment groups outperformed the control groups on ratings of eye contact, declarative "no" responses, statements expressing refusal to risk pregnancy, and requests that partners share in responsibility for birth control. The treatment groups also reported improved contraceptive practices that were maintained at 6-month follow-up. Schinke et al. (1981) report that the participating teachers, parents, and subjects enjoyed the intervention and found it to be quite valuable.

The Schinke et al. (1981) intervention serves as an excellent model for the future development of sexual-interaction skills training interventions with adolescents. Key factors contributing to the success of this intervention likely include its use of (a) a comprehensive assessment battery and curriculum, including sexual knowledge and specific sexual-interaction skills; (b) the school setting for training; (c) multiple teaching modalities (e.g., audiovisual, guest speakers); (d) a group skills training format that allowed continued practice of targeted skills with multiple peers; (e) monitored practice of skills outside the sessions using behavioral contracting; and (f) training that focused on the specific situations of interest (i.e., sexual).

Although their study was not targeted directly at adolescents, Kelly et al. (1989) provide another powerful example of the use of social-skills training procedures in an intervention that effectively reduced high-risk sexual practices. The subjects were 51 men aged 21 years or older (mean age $=31$ years) who were self-identified as either homosexual or bisexual. Social-skills training served as a major component of the intervention that also included problem-solving training directed specifically at sexual decisions, AIDS risk education, and behavioral self-management training. Over the course of three sessions, participants were taught skills for both initiating discussions about low-risk sexual behaviors with their partners and refusing coercions to engage in high-risk sexual behaviors. For exam- 
ple, sexual-assertiveness components included training participants to respond to a partner's coercive attempts to engage them in highrisk practices by acknowledging but firmly refusing the unsafe request, providing a rationale for the refusal, and suggesting a low-risk alternative.

Subjects in the treatment group showed significant improvements on role-play ratings of declining propositions, initiating discussions about low-risk sexual activities, refusing unsafe sex, providing reasons for refusing unsafe requests, and suggesting lower-risk alternatives. Four-month postintervention assessments revealed that the experimental group participated in significantly fewer highrisk sexual practices (e.g., unprotected anal intercourse, infrequent condom use) than did the control group and that these differences were maintained over a 24-month period. There is a strong need for evaluations of this type of comprehensive intervention with adolescents.

\section{SUMMARY AND FUTURE DIRECTIONS}

Although the application of social-skills training procedures appears promising, more research is needed to determine and empirically validate exactly what specific skills are associated with competent sexual interactions. The failure to demonstrate that behaviors targeted for intervention are related to successful interpersonal interactions is a general weakness of the adolescent social-skills training literature (Hansen, Watson-Perczel, \& Christopher, 1989).Some potential lines of inquiry for sexual interaction assessment research include (a) What is the nature of heterosocial-sexual competence? (b) What skills compose such competence in various sexual interactions? and (c) What is the relation between sexual-interaction skills, sexualinteraction problems, and the various major problems associated with sexual behavior of adolescents?

Future research should begin to elucidate further the relations between specific communication-, assertion-, and problem-solving skills deficits and the problems associated with adolescent sexual activity. Promising targets include the specific skills needed to (a) appropri- 
ately initiate, maintain, or decline sexual activity with a member of the opposite sex; (b) communicate important sexual information to a prospective partner, such as telling a partner about an STD or level of desired sexual activity; (c) carry through with safer-sex practices, such as informing a partner that a condom must be used; (d) report a sexual attack to the proper authorities; and (e) make informed sexual decisions, such as deciding who is an appropriate sexual partner, what are appropriate times to initiate a sexual relationship, whether or not to discontinue a sexual relationship, what are appropriate contraceptive methods, what is the appropriate action if victimized by sexual assault, and where to find appropriate health care if an STD is contracted or one becomes pregnant.

The further refinement and development of adequate assessment methods will assist in the evaluation of the proposed social-skills training interventions. Fundamental elements of such evaluative research should include (a) evaluations of specific components of training procedures, (b) repeated measurements of specific components of training procedures, (c) assessment of these specific skills in the natural environment, and (d) more global assessment of collateral behaviors, such as actual contraceptive practices or the actual occurrence of problems such as STDs, pregnancy, and date rape.

The current AIDS threat has caused American society to reconsider the sexual practices of its members. However, many serious problems related to sexual practices besides AIDS currently affect our adolescent population. This age group is at high risk for all problems associated with sexual activity, such as sexually transmitted diseases, pregnancy, and date rape. These problems have caused inestimable harm to millions of adolescents and their families, in addition to the costs to society. The growing support for the ability of programs combining education and skills training to change such behavior (e.g., Kelly et al., 1989; Schinke et al., 1981) warrants further investigation. As evidenced in this article, the social-skills training literature provides a strong basis for the development of innovative targets and skills-training procedures aimed at changing the sexual practices of adolescents. 


\section{REFERENCES}

Arkowitz, H. (1977). Measurement and modification of minimal dating behavior. In M. Hersen, R. M. Eisler, \& P. M. Miller (Eds.), Progress in behavior modification (Vol. 5, pp. 1-61). New York: Academic Press.

Arkowitz, H., Hinton, R., Perl, J., \& Himadi, W. (1978). Treatment strategies for dating anxiety in college men based on real-life practice. Counseling Psychologist, 7, 41-46.

Balassone, M. L. (1989). Risk of contraceptive discontinuation among adolescents. Journal of Adolescent Health Care, 10, 527-533.

Bandura, A. (1969). Principles of behavior modification. New York: Holt, Rinehart, \& Winston.

Barlow, D. H. (1977). Assessment of sexual behavior. In A. R. Ciminero, K. S. Calhoun, \& H. E. Adams (Eds.), Handbook of behavioral assessment (pp. 461-508). New York: Wiley.

Barlow, D. H., Abel, G. G., Blanchard, E. B., Bristow, A. R., \& Young, L. D. (1977). A heterosocial skills behavior checklist for males. Behavior Therapy, 2, 229-239.

Beck, J. G., \& Davies, D. K. (1987). Teen contraception: A review of perspectives on compliance. Archives of Sexual Behavior, 16, 337-368.

Bellack, A. S., Hersen, M., \& Lamparski, D. (1979). Role-play tests for assessing social skills: Are they valid? Are they useful? Journal of Consulting and Clinical Psychology, 47, 335-342.

Berger, K. S. (1986). The developing person through childhood and adolescence (2nd ed.). New York: Worth.

Bradlyn, A. S., Himadi, W. G., Crimmins, D. B., Christoff, K. A., Graves, K. G., \& Kelly, J. A. (1983). Conversational skills training for retarded adolescents. Behavior Therapy, 14, 314-325.

Bruch, M. A., \& Hynes, M. J. (1987). Heterosocial anxiety and contraceptive behavior. Journal of Research in Personality, 21, 343-360.

Burger, J. M., \& Inderbitzen, H. M. (1985). Predicting contraceptive behavior among college students: The role of communication, knowledge, sexual anxiety, and self-esteem. Archives of Sexual Behavior, 14, 343-350.

Byrne, D. (1983). Sex without contraception. In D. Byrne \& W. A. Fisher (Eds.), Adolescents, sex, and contraception (pp. 3-31). Hillsdale, NJ: Lawrence Erlbaum.

Catania, J. A., Kegeles, S. M., \& Coates, T. J. (1990). Towards an understanding of risk behavior: An AIDS risk reduction model (ARRM). Health Education Quarterly, 17, 53-72.

Check, J. V. P., \& Malamuth, N. M. (1983). Sex role stereotyping and reactions to depictions of stranger versus acquaintance rape. Journal of Personality and Social Psychology, 45, 344-356.

Chilman, C. S. (1983). Adolescent sexuality in a changing American society (2nd ed.). New York: Wiley.

Christoff, K. A., Scott, W. O. N., Kelley, M. L., Schlundt, D., Baer, G., \& Kelly, J. A. (1985). Social skills and social problem-solving training for shy young adolescents. Behavior Therapy, 16, 468-477.

Conger, J. C., \& Conger, A. J. (1982). Components of heterosocial competence. In J. P. Curran \& P. M. Monti (Eds.), Social skills training: A practical handbook for assessment and treatment (pp. 313-347). New York: Guilford. 
Csikszentmihalyi, M., \& Larson, R. (1984). Being adolescent: Conflict and growth in the teenage years. New York: Basic Books.

Curran, J. P. (1977). Skills training as an approach to the treatment of heterosexual-social anxiety: A review. Psychological Bulletin, 84, 140-157.

Cvetkovich, G., \& Grote, B. (1981). Psychosocial maturity and teenage contraceptive use: An investigation of decision-making and communication skills. Population and Environment, 4, 211-226.

Damon, W. (1983). Social and personality development. New York: Norton.

DiClemente, R. J. (1990). The emergence of adolescents as a risk group for human immunodeficiency virus infection. Journal of Adolescent Research, 5, 7-17.

Ford, C., \& Beach, F. (1951). Patterns of sexual behavior. New York: Harper \& Row.

Gagnon, J., \& Simon, W. (1973). Sexual conduct. Chicago: Aldine.

Galassi, J. P., \& Galassi, M. D. (1979). Modification of heterosocial skills deficits. In A. S. Bellack \& M. Hersen (Eds.), Research and practice in social skill training (pp. 131187). New York: Plenum.

Goodman, E., \& Cohall, A. T. (1989). Acquired immunodeficiency syndrome and adolescents: Knowledge, attitudes, beliefs, and behaviors in a New York City adolescent minority population. Pediatrics, 84, 36-42.

Hansen, D. J., Christopher, J. S., \& Nangle, D. W. (1992). Adolescent heterosocial interactions and dating. In V. B. Van Hasselt \& M. Hersen (Eds.), Handbook of social development: A lifespan perspective (pp. 371-394). New York: Plenum.

Hansen, D. J., St. Lawrence, J. S., \& Christoff, K. A. (1989). Group conversational-skills training with inpatient children and adolescents: Social validation, generalization, and maintenance. Behavior Modification, 13, 4-31.

Hansen, D. J., Watson-Perczel, M., \& Christopher, J. S. (1989). Clinical issues in socialskills training with adolescents. Clinical Psychology Review, 9, 365-391.

Hartup, W. W. (1983). Peer interaction and the behavioral development of the individual child. In W. Damon (Ed.), Social and personality development: Essays on the growth of the child (pp. 220-233). New York: Norton.

Hingson, R. W., Strunin, L., Berlin, B. M., \& Heeren, T. (1990). Beliefs about AIDS, use of alcohol and drugs, and unprotected sex among Massachusetts adolescents. American Journal of Public Health, 80, 295-299.

Huszti, H. C., Clopton, J. R., \& Mason, P. J. (1989). Acquired immunodeficiency syndrome educational program: Effects on adolescents' knowledge and attitudes. Pediatrics, 84, 986-994.

Hynes, M. J., \& Bruch, M. A. (1985). Social skills and responses in simulated contraceptive problem situations. Journal of Sex Research, 21, 422-436.

Jemmott, L. S., \& Jemmott, J. B. (1 990). Sexual knowledge, attitudes, and risky sexual behavior among inner-city black male adolescents. Journal of Adolescent Research, 5, 346-369.

Kazdin, A. E., Esveldt-Dawson, K., French, N. H., \& Unis, A. S. (1987). Problem-solving skills training and relationship therapy in the treatment of antisocial child behavior. Journal of Consulting and Clinical Psychology, 55, 76-85.

Kelly. J. A. (1982). Social-skills training: A practical guide for interventions. New York: Springer.

Kelly, J. A., \& Hansen, D. J. (1987). Social interactions and adjustment. In V. B. Van Hasselt \& M. Hersen (Eds.), Handbook of adolescent psychology (pp. 131-146). New York: Pergamon. 
Kelly, J. A., \& St. Lawrence, J. S. (1988). The AIDS health crisis: Psychological and social interventions. New York: Plenum.

Kelly, J. A., St. Lawrence, J. S., Hood, H. V., \& Brasfield, T. L. (1989). Behavioral intervention to reduce AIDS risk activities. Journal of Consulting and Clinical Psychology, 57, 60-67.

Kirkland, K. D., Thelen, M. H., \& Miller, D. J. (1982). Group assertion training with adolescents. Child \& Family Behavior Therapy, 4(4), 1-13.

Knox, D., \& Wilson, K. (1983). Dating problems of university students. College Student Journal, 17, 225-228.

Koenig, M. A., \& Zelnick, M. (1982). The risk of premarital first pregnancy among metropolitan-area teenagers: 1976 and 1979. Family Planning Perspectives, 14, 239-247.

Leary, M. R., \& Dobbins, S. E. (1983). Social anxiety, sexual anxiety, and contraceptive behavior. Journal of Personality and Social Psychology, 45, 1347-1354.

Lee, D. Y., Hallberg, E. T., \& Hassard, H. (1979). Effects of assertion training on aggressive behavior of adolescents. Journal of Counseling Psychology, 26, 459-461.

Lundberg-Love, P., \& Geffner, R. (1989). Date rape: Prevalence, risk factors, and a proposed model. In M. A. Pirog-Good \& J. E. Stets (Eds.), Violence in dating relationships: Emerging social issues (pp. 169-184). New York: Praeger.

MacDonald, N. E., Wells, G. A., Fisher, W. A., Warren, W. K., King, M. A., Doherty, J. A., \& Bowie, W. R. (1990). High-risk STD/HIV behavior among college students. Journal of the American Medical Association, 263, 3155-3159.

McCabe, M. P. (1984). Toward a theory of adolescent dating. Adolescence, 19, 159-170.

McFall, R. M. (1982). A review and reformulation of the concept of social skills. Behavioral Assessment, 4, 1-33.

Melchert, T., \& Burnett, K. F. (1990). Attitudes, knowledge, and sexual behavior of highrisk adolescents: Implications for counseling and sexuality education. Journal of Counseling and Development, 68, 293-298.

Miller, B. C., McCoy, J. K., \& Olson, T. D. (1986). Dating age and stage as correlates of adolescent sexual attitudes and behavior. Journal of Adolescent Research, 1, 361-377.

Muehlenhard, C. L., \& Linton, M. A. (1987). Date rape and sexual aggression in dating situations: Incidence and risk factors. Journal of Counseling Psychology, 34, 186-196.

Murnen, S. K., Perot, A., \& Byrne, D. (1989). Coping with unwanted sexual activity: Normative responses, situational determinants, and individual differences. Journal of Sex Research, 26, 85-106.

Nangle, D. W., Giacoletti, A. M., Ellis, J. T., Aljazireh, L., \& Hansen, D. J. (1992). Contraceptive behavior among young adults: A descriptive component analysis. Manuscript submitted for publication.

Oskamp, S., \& Mindick, B. (1983). Personality and attitudinal barriers to contraception. In D. Byrne \& W. A. Fisher (Eds.), Adolescents, sex, and contraception (pp. 65-107). Hillsdale, NJ: Lawrence Erlbaum.

Peterson, A. C., \& Hamburg, B. A. (1986). Adolescence: A developmental approach to problems and psychopathology. Behavior Therapy, 17, 480-499.

Plienis, A. J., Hansen, D. J., Ford, F., Smith, S., Stark, L., \& Kelly, J. A. (1987). Behavioral small group training to improve the social skills of emotionally-disordered adolescents. Behavior Therapy, 18, 17-32.

Rhodes, W. A., Redd, W. H., \& Berggren, L. (1979). Social skills training for an unassert- 
ive adolescent. Journal of Child Clinical Psychology, 3, 18-21.

Roscoe, B., \& Kruger, T. L. (1990). AIDS: Late adolescents' knowledge and its influence on sexual behavior. Adolescence, 25, 39-48.

Rotherman, M. J., \& Armstrong, M. (1980). Assertiveness training with high school students. Adolescence, 15, 267-276.

Schinke, S. P., Blythe, B. I., \& Gilchrest, L. D. (1981). Cognitive-behavioral prevention of adolescent pregnancy. Journal of Counseling Psychology, 28, 451-454.

Schwartz, R. M., \& Gottman, J. M. (1976). Toward a task analysis of assertive behavior. Journal of Consulting and Clinical Psychology, 41, 910-920.

Select Committee on Children, Youth, and Families, U. S. House of Representatives. (1988). AIDS and teenagers: Emerging issues. Washington, DC: U.S. Government Printing Office.

Shure, M. B., \& Spivack, G. (1972). Means-end thinking, adjustment, and social class among elementary-school-aged children. Journal of Consulting and Clinical Psychology, 41, 910-920.

Sonenstein, F. L., Pleck, J. H., \& Ku, L. C. (1989). Sexual activity, condom use and AIDS awareness among adolescent males. Family Planning Perspectives, 21, 152-158.

Stake, J. E., DeVille, C. J., \& Pennell, C. L. (1983). The effects of assertiveness training on the self-esteem of adolescent girls. Journal of Youth and Adolescence, 12, 435-442.

Tisdelle, D. A., \& St. Lawrence, J. S. (1988). Adolescent interpersonal problem-solving skill training: Social validation and generalization. Behavior Therapy, 19, 171-182.

Warren, N. J., \& Gilner, F. H. (1978). Measurement of positive assertive behaviors: The behavioral test of tenderness expression. Behavior Therapy, 9, 178-184.

Weisman, C. S., Plichta, S., Nathanson, C. A., Ensminger. M., \& Robinson, J. C. (1991). Consistency of condom use for disease prevention among adolescent users of oral contraceptives. Family Planning Perspectives, 23, 71-74.

Douglas W. Nangle M.A., is currently a Clinical Psychology Resident at the University of Mississippi Medical Center $\mathrm{He}$ is a doctoral candidate in the Child Clinical Psychology Program at West Virginia University and a 1986 magna cum laude graduate of the State University of New York at Stony Brook. His research interests include child and adolescent social competence, heterosocial interactions, contraceptive behavior and behavioral AIDS-risk reduction.

David J. Hansen Ph.D., is an Associate Professor of Psychology and Director of the Psychological Consultation Center at the University of Nebraska-Lincoln. His research interests include child and adolescent social competence and behavioral assessment and treatment of maltreating families. 